\title{
CONSIDERAÇÕES SOBRE O CANABIDIOL NO PROCESSO PSICOTERAPÊUTICO DE CRIANÇAS COM TRANSTORNO DO ESPECTRO AUTISTA
}

\author{
CONSIDERATIONS ON THE CANNABIDIOL IN THE PSYCHOTHERAPY \\ PROCESS OF CHILDREN WITH AUTISTIC SPECTRUM DISORDER.
}

\begin{abstract}
Allana Daiara Correia Oliveira ${ }^{1^{*}}$, Caroline Andrea Pottker ${ }^{2}$
${ }^{1}$ Discente do curso de graduação em Psicologia da UNINGÁ - Centro Universitário Ingá (Maringá/PR).

${ }^{2}$ Doutoranda em Psicologia na Universidade Estadual de Maringá. Professora Mestre do Curso de Psicologia da UNINGÁ - Centro Universitário Ingá (Maringá/PR).

* Rua: Dr. Ewert Eugênio de A. Nogueira, no 156, Vila Esperança, Maringá - Paraná. CEP: 87020-560. E-mail: allana_daiara@yahoo.com.br.
\end{abstract}

Submetido em: 26/09/2019; Aceito em:12/12/2019.

\section{RESUMO}

O presente artigo tem como objetivo discutir como os efeitos do canabidiol podem contribuir para o processo psicoterapêutico da criança com Transtorno do Espectro Autista (TEA). Para tanto, foram realizadas pesquisas em bancos de dados e indexadores, sobre o tema em questão, selecionando os artigos referentes à área da Psicologia, TEA e Canabidiol. Entende-se como Transtorno do Espectro Autista um transtorno do neurodesenvolvimento, comprometendo a comunicação verbal, interação social e desenvolvendo comportamentos estereotipados. Como forma de tratamento tem sido indicado uma das várias substâncias da Cannabis sativa que possui potencial terapêutico, o canabidiol (CBD) que tem como benefícios a diminuição da agressividade, insônia, hiperatividade, entre outros sintomas. Desse modo, o uso do óleo da Cannabis sativa (CBD) exerce uma função fitoterápica, que atua na diminuição dos sintomas e auxilia num melhor aproveitamento do processo psicoterápico. Portanto, a criança com TEA que faz uso do CBD melhora sua percepção, atenção, interação social, bem como, a diminuição de quadros ansiosos, o que contribui para uma melhor adesão psicoterapêutica.

PALAVRAS-CHAVE: Canabidiol. Psicoterapia. TEA.

\section{ABSTRACT}

The article aims to discuss how the effects of cannabidiol can contribute to the psychotherapy process of a child with Autistic Spectrum Disorder (ASD). Therefore, research was conducted on databases and indexers, about the subject, selecting the articles referred to the psychology area, ASD and Cannabidiol. Autistic Spectrum Disorder (ASD), is understood as a disorder of neurodevelopment, affecting verbal communication, social interaction and developing stereotyped behaviors. The Cannabidiol (CBD), one of several substances of the Cannabis sativa, has been indicated as a treatment form and 
its benefits include the decrease of aggression, insomnia, hyperactivity, among other symptoms. That way, the use of the Cannabis sativa oil (CBD), has a phytotherapic function, acts in the decrease of symptoms and assists in a better advantage of the psychotherapy process. As a result, the children with ASD who make the use of the CBD, improve their perception, attention, social interaction, as well as, decrease anxiety symptoms, which contributes to a better psychotherapy adhesion.

KEYWORDS: ASD. Cannabidiol. Psychotherapy.

\section{INTRODUÇÃO}

Em nosso país, desde 1830 a Cannabis sativa, nome científico dado a maconha, passou a ser considerado substância ilegal. De acordo com Barros e Peres (2011), a maconha é vista desta forma desde que a família real e poderes executivos da época associaram seu uso apenas a pessoas negras, escravos e índios, alegando que os mesmos abusavam da substância associada ao álcool, por vezes demonstravam comportamentos agressivos, sonolência e alucinação, culpabilizando a maconha por uma série de fatores negativos $\mathrm{e}$ estereotipando o uso a pessoas "vagabundas e ociosas", decidindo assim, criminalizá-la. Desde então, a maconha passa a ser uma droga ilícita e todas as potencialidades terapêuticas usadas há 5.000 anos a.C perdem seus valores.

Historicamente, como vimos, se enraizou preconceitos sociais ao que concerne o uso tanto recreativo quanto fitoterápico da $C$. sativa. Criou-se um tabu na sociedade onde considera-se apenas as potencias psicoativas e alucinógenas da planta, esta visão passa a ser sustentada pela população e governo desde a Convenção Internacional sobre o Ópio, organizada pela Liga das Nações, em Haia, no ano de 1912 que torna a criminalização da Cannabis Sativa internacional, obrigando as culturas da época "renunciar" o uso dos recursos terapêuticos da planta (BARROS; PERES, 2011).

Contudo, uma das várias substâncias da Cannabis sativa que possui potencial terapêutico é canabidiol (CBD), que tem como benefícios a diminuição da agressividade, insônia, hiperatividade entre outros. Barros e Peres (2011) apontam o uso da $C$. sativa em forma de óleo por tribos para tratar Parkinson, esclerose múltiplas, Alzheimer, crises convulsivas, dor crônica e sintomas que hoje são associados ao TEA.

O Transtorno do Espectro Autista (TEA) é um transtorno de neurodesenvolvimento que prejudica a comunicação, habilidade social, sistema sensorial, planejamento motor e comportamentos estereotipados. Atualmente o tratamento para o TEA é para diminuição dos sintomas ocasionados pelo transtorno, este tratamento consiste tanto a nível medicamentoso quanto psicoterapias e trabalhos terapêuticos com equipe multidisciplinar. Para Oliveira e Sertié (2017) a psicoterapia fornece instrumentos para este paciente na finalidade de diminuir as dificuldades da interação social e desenvolver autonomia e independência.

Várias classes de fármacos são utilizadas para melhora dos sintomas do TEA, como risperidona, clonazapan, diazepam, fluoxetina, ritalina e alguns estabilizadores de humor, mas os efeitos colaterais desses fármacos, em alguns 
casos, podem desencadear quadros de insônia, compulsão alimentar, agressividade e irritabilidade (CARTILHA DIREITO DAS PESSOAS COM AUTISMO, 2011). Entretanto, Ribeiro e Lopes (2007) salientam que o uso do óleo CBD como recurso fitoterápico que proporciona melhoras significativas em crianças autistas em relação a quadros de agressividade, depressivo e ansiolítico, proporcionando uma melhora no convívio social e ensinoaprendizagem.

Assim, o objetivo desse trabalho é discutir como os efeitos do canabidiol podem contribuir para o processo psicoterapêutico da criança com Transtorno do Espectro Autista. Para tanto, é de grande relevância apresentar informações e possibilidades de avanços no tratamento de crianças com TEA, tanto farmacológico quanto psicoterapêutico. As contribuições presentes, abrem espaço para se debater o impacto que o canabidiol desencadeia no organismo da criança, e o aproveitamento que o mesmo consegue obter nas psicoterapias.

\section{METODOLOGIA}

A revisão bibliográfica narrativa, ou revisão de literatura, é a análise crítica e minuciosa, que abrange publicações científicas em uma determinada área do conhecimento (LIMA; MIOTO, 2007), possibilitando ao pesquisador a interpretação das informações coletadas. No presente trabalho, utilizamos como recursos de pesquisa bibliográficas artigos científicos do Scielo, Pepsic e Google Acadêmico, dissertações de mestrado, livros e publicações cientificas online. Para esta revisão foram analisados artigos a partir do ano de dois mil (2000), tanto no português, quanto no inglês e espanhol.

Esta pesquisa utilizou como critério de seleção apenas artigos que descreviam através de pesquisas qualitativas ou quantitativas, resultados fitoterápicos do canabidiol em humanos e, principalmente, aplicado em crianças com quadros de TEA, epilepsia e comorbidades, desse modo, visa conhecer e analisar conteúdos científicos, englobando o maior número possível de materiais sobre canabidiol, TEA e psicoterapia. Foram realizadas revisões literárias para dar consistência, coerência e confiabilidade no trabalho apresentado, assim a pesquisa contemplou diferentes áreas de pesquisas acadêmicas como a psiquiatria, história, nutrição e psicologia.

Dessa maneira os conteúdos analisados partiram dos seguintes critérios: História da C. sativa, propriedades medicinais e sua aplicação a medicina alternativa, história do Autismo, grupos de experimentos do Canabidiol aplicada ao Autismo, Autismo e recursos psicoterapêuticos.

\section{DESENVOLVIMENTO}

\section{TEA: Principais características}

Houve um aumento significativo, durante as últimas três décadas no número de crianças diagnosticadas com transtorno do espectro autista em todo o mundo. O transtorno do Espectro autista (TEA) possui fatores genéticos, ambientais e manifestações orgânicas, que podem iniciar na mais tenra idade, podendo se agravar com o passar do tempo. Por conseguinte, este Transtorno é caracterizado por movimentos estereotipados, ausência ou não da fala, em 
alguns casos hipersensibilidade (sonora, visual, tátil) e convulsões, agressividade, ausência de socialização e empatia (OLIVEIRA; SERTIÉ, 2017).

Desse modo, a criança com TEA apresenta sintomas desde os seis meses de vida, como apontam Oliveira e Sertié (2017) podendo se agravar com o passar do tempo, mas o diagnóstico conclusivo ocorrerá a partir dos três anos, pois esta fase caracteriza-se pelo atraso no desenvolvimento correspondente a idade da criança.

\footnotetext{
"O atraso para adquirir o sorriso social, demonstrar interesse em objetos sorrindo para eles e movimentando o corpinho em detrimento a desinteresse ou pouco interesse pela face humana, o olhar não sustentado ou ausente, a preferência por dormir sozinho no berço e demonstrar irritabilidade quando ninado no colo, a ausência da ansiedade de separação e indiferença quando os pais se ausentam podem ser sinais precoces que indicam que o desenvolvimento precisa ser avaliado e que há a necessidade de estimulação precoce focada na socialização, linguagem e afeto dessa criança. Cabe ao pediatra inserir essa investigação nas consultas de puericultura" (SOCIEDADE BRASILEIRA DE PEDIATRIA, 2017).
}

Como citado acima o TEA é um transtorno que pode desencadear intensos déficits comunicativos, levando-as a um processo de afastamento social por não conseguirem se expressar. Diante disso, alguns comportamentos como gritos, choro sem causalidade identificada, autoestimulação e utilização do corpo do outro para alcançar seu objetivo, são estratégias usadas pelas crianças com autismo. Outrossim, em alguns casos crianças com autismo demonstram comportamentos agressivos quando contrariadas e/ou tiradas da rotina estabelecida (FITZPATRICK et al., 2016).

Os mesmos autores complementam que esses comportamentos agressivos podem ter funções tanto de heteroagressão, dirigidos para o mundo externo, quanto autoagressão, dirigidos para si próprio. Entende-se que o excesso de estímulos externos pode desencadear diversas sensações internas, justificando os comportamentos agressivos, que muitas vezes podem funcionar como autorregulador, ou seja, um mecanismo que busca adaptação e/ou foco quando o excesso de estímulos ocasionado por uma desregulação neuronal, seja visual, auditivo, motor, gustativo ou sensorial acarretam em um desajuste orgânico (POSAR; VISCONTI, 2017). Posto isto, desenvolver técnicas de mapeamento para a criança com TEA diminui alguns impactos que ocasionam essa desregulação, por exemplo, em uma sala muito ampla sinalizar o chão com tapetes de E.V.A, fitas coloridas ou outros recursos visuais que tragam a noção espacial favorecem na autorregulação.

Semelhantemente, Serrano (2016) argumenta que alguns autistas demonstram ter sensibilidade olfativa, como cheiros fortes, por exemplo perfumes, e tátil, com extrema dificuldade em manipular diferentes tipos de texturas, dificuldade de ser tocado e de tocar o outro. Esses comportamentos podem ocasionar redução da qualidade de vida, falta de sono, ansiedade, além de dificuldades no contexto escolar e familiar, funcionando como gatilhos desreguladores (WALLACE, 2018). Assim, entende-se que compreender os gatilhos desreguladores, possibilita ao psicoterapeuta um entendimento total dos 
comportamentos autorreguladores, identificar quais os estímulos que causam transbordamento abrem espaço para maiores intervenções.

As causas do TEA ainda não estão definidas e não existe cura para 0 transtorno, porém já se sabe que o autismo é mais comum em crianças do sexo masculino e que as manifestações em meninas são mais sutis e difícil de ser diagnosticado. O TEA se desenvolve independente do grupo sociocultural, origem geográfica ou situação socioeconômica, sabe-se que fatores genéticos, ambientais, impactos que o cérebro do bebê sofreu tanto no pré-natal quanto no pós-natal e a prematuridade estão ligados. Ao se realizar o exame clinico para fins diagnósticos estas causas são alvos de investigação (SILVA; MULICK, 2009).

O diagnóstico do TEA é feito por avaliação clínica, em conjunto com critérios específicos propostos pelo Código Internacional de Doenças (CID-10) e o Manual Diagnóstico e Estatístico de Transtornos Mentais (DSM-V). Conforme Silva e Mulick (2009) o diagnóstico deve seguir de um planejamento de intervenção, quanto antes realizar este diagnóstico, melhor para intervenção precoce, uma vez que é na primeira infância que a neuroplasticidade está se construindo e formando conexões sinápticas que moldaram a constituição do comportamento e cognição.

Além disso, não existe medicamentos específicos para o autismo, mas algumas medicações podem ser receitadas para diminuição dos sintomas ou quando há outras doenças associadas, como epilepsia, transtorno bipolar e hiperatividade. As classes mais utilizadas de fármacos são os antipsicótico (risperidona), benzodiazepínicos (clonazepam), ansiolíticos (diazepam), inibidores seletivos da recaptação de serotonina (fluoxetina e sertralina), psicoestimulantes (ritalina), estabilizadores de humor (divalproato de sódio, indicados principalmente para 0 tratamento do Transtorno Bipolar) e anticonvulsivantes (ácido valproico que atuam na regulação dos sintomas). Embora tenham efeitos colaterais como insônia ou sonolência, perda de apetite, irritabilidade, agressividade entre outros, são as classes mais utilizadas para alívio dos sintomas, como podemos ver em outro tópico (CARTILHA DIREITO DAS PESSOAS COM AUTISMO, 2011).

Além dos medicamentos citados acima, o uso do óleo da $C$. sativa (CBD) demonstra através de vários estudos laboratoriais benefícios para o paciente com autismo. Ao passo que o CBD atua na regulação psicológica e física, proporciona também possibilidades de atuação em todo organismo. Sendo assim, Bueno (2014) constata que o CBD atuará como repositor dos endocanabinóides já encontrados no corpo humano, agindo como regulador das funções internas e externas, como veremos a seguir.

De acordo com a Cartilha Direitos das pessoas com autismo (2011) o uso de medicamentos deve ser prescrito por médicos especialistas e em conjunto 0 paciente deve receber atendimento terapêutico, de forma multidisciplinar, como fonoaudiólogos, fisioterapeutas, terapeutas ocupacionais, psicólogos, assistentes sociais e quando possível, um educador físico. A equipe trabalha em conjunto, levando em consideração a subjetividade de cada paciente, o contexto que está inserido e suas limitações tanto cognitivas, quanto física. Dentre tantos medicamentos citados, a presente pesquisa destaca o óleo do Canabidiol para o tratamento do TEA, vejamos quais são seus efeitos no corpo humano. 


\section{O Canabidiol e seus efeitos no corpo humano}

Novos estudos apontaram a existência do sistema endocanabinóide no corpo humano, que ativam receptores específicos no cérebro. Este sistema tem como função regular apetite, humor, sono, sistema imunológico, dor, inflamações, metabolismo, digestão, memória e proteção do desenvolvimento dos neurônios. Outrossim, o corpo humano é cheio de receptores endocanabinóides, que são mensageiros naturais do corpo humano, podendo ser encontrados nas células, tecidos e no organismo (BUENO, 2014).

O sistema endocanabinóide é feito de duas células receptoras principais, sendo estas, CB1 que se encontra na medula espinal e no cérebro, e CB2 encontrados nas células imunes e no sistema nervoso, as células receptoras do corpo funcionam como cadeados e cada cadeado tem sua chave correspondente, chamadas de agonistas. As chaves agonistas, conforme Bueno (2014) desses receptores são os canabinóides que são produzidos no corpo, e também os canabinóides que vem de fora, como da $C$. sativa.

O mesmo autor aponta que os canabinóides são distribuídos pelo corpo humano e divididos em duas categorias, sendo estas, endógeno que significa que é produzido pelo corpo humano, interagindo com os receptores, com a função de regular humor, apetite, dor, sono, entre outros. Por conseguinte, encontramos o canabinóide cxógeno, esta categoria vem de fora do corpo, por exemplo, por meio do óleo da $C$. sativa, atuando no corpo através de modificações físicas e psicológicas.

A partir disso, estudos apontam que crianças com TEA não possuem homeostase nas células do sistema endocanabinóide (células CB1 E CB2) e sem excesso de atividades cerebrais. Portanto, para Lopes (2014) o uso do óleo da C. sativa (CBD/THC) funciona no organismo dessa criança como um agonista, propiciando homeostase no corpo, através dos receptores CB1 E CB2, ajustamento na produção de serotonina e regulando o excesso de atividades neuronais.

Atualmente, novas pesquisas estão sendo realizados, ao que tange o uso medicinal do óleo da C. sativa. De acordo com a Secretaria da Saúde do Mato Grosso do Sul, a $C$. sativa é uma planta que contém mais de 400 substâncias químicas, mas apenas 60 se classificam na categoria terapêutica. Portanto, podemos dividir a $C$. sativa em duas propriedades, sendo estas, a tetrahidrocarbinol (THC) que tem propriedades psicotrópicas e alucinógenas, capaz de causar dependência psicológica nos usuários, ou seja, dependência sobre as sensações de prazer psíquica que o THC desperta. O canabidiol (CBD) representa mais de $40 \%$ de seus extratos terapêuticos, é do canabidiol que se faz o óleo da $C$. sativa, utilizado para fins medicinais (SECRETARIA DE ESTADO DE SAÚDE, 2015).

Ao contrário do que alguns autores abordam, o CBD não deixa a criança alucinada, pois suas substâncias psicoativas são descartadas praticamente por completo, para a manipulação do óleo de canabidiol o nível de CBD é muito maior sobre o THC, por exemplo, 9,9\% de CBD e $0,1 \%$ de THC, a medicação é formulada de acordo com as necessidades do paciente. Mas, no momento não 
se trabalha com total garantia de confiabilidade do uso de THC sem efeitos colaterais e psicoativos (CRIPPA et al., 2016).

Entendendo que o CBD atua nas atividades cerebrais e físicas, seu potencial terapêutico será de regulação nas funções que se encontram com hiperestimulação ou com pouca estimulação. Segundo Crippa et al., (2016) há registros de utilização de CBD para epilepsia em pacientes de autismo severo, e que obtiveram como fins terapêuticos, além do controle e diminuição das crises epilépticas, auxiliou na regulação do apetite, sono, ansiedade, agressividade, autoestimulação e em alguns casos início da fala.

Consequentemente, o CBD atua no organismo do paciente com fins terapêuticos, sendo estes, ação ansiolítica, antipsicótico, proteção dos neurônios, anti-inflamatória, antiepilética, déficits cognitivos e nos distúrbios do sono. É sabido, que ao modular as atividades cerebrais, o CBD também auxilia nas funções intestinais, melhora e/ou regulação do apetite, percepção e concentração (SCHLEIDER; MEIRI; NOVACK, 2019). De modo similar, Santos (2016) ressalta que o uso do óleo da $C$. sativa diminui comportamentos agressivos, muitas vezes ocasionados por isolamento social, dificuldade de comunicação e hiperatividade.

Em vista disso, a utilização do óleo da C. sativa (CBD) isoladamente não traria benefícios significativos ao desenvolvimento desta criança, por isso a psicoterapia vem sendo reconhecida no tratamento do TEA, em conjunto com CBD possibilita o desenvolvimento e a construção de novas possibilidades para a criança com TEA.

\section{Canabidiol e o processo psicoterápico}

A Psicoterapia Infantil é o acompanhamento psicológico que pode ser realizado através da ludoterapia ou o brincar, esta técnica consiste em facilitar as manifestações da fantasia e sentimentos da criança. Neste processo de Psicoterapia a criança encontrará um ambiente de interação, favorecendo espaço para a expressão das vivencias e integração dos sentimentos. Dessa forma, através do brincar no processo psicoterapêutico, a criança com TEA será instrumentalizado com recursos psicoterapêuticos que irão auxiliar no enfrentamento e superação dos problemas emocionais e comportamentais. Sendo assim, a psicoterapia tem como objetivo melhorar a qualidade de vida da criança com TEA, promovendo autonomia, bem-estar emocional, desenvolvimento de habilidades sociais, comunicação e afetividade, contribuindo para uma infância prazerosa e enfrentamento das diferenças pessoais, assim a criança conduz o brincar, da maneira que ela se senti segura e confortável (SOUZA et al., 2004).

O psicólogo que realiza esse atendimento, deve ter uma capacidade de identificar as necessidades da criança com TEA e se necessário adaptar os recursos psicoterapêutico para evolução da sessão. Dessa maneira, o lúdico é o recurso mais utilizado, como massinha de modelar, desenhos, brincadeiras de faz-de-conta, colagem, pintura entre outros materiais que a criança se identificar, são recursos disponíveis para o psicoterapeuta. Neste processo, a criança irá não somente projeta sentimentos, angústias, agressividade e anseios, mas também aprenderá sobre vínculo, contato social, afetividade, autorrealização, comunicação entre outros benefícios que em contato com a psicoterapia, em um 
processo de mão dupla se desenvolve. Assim sendo, Homem (2009) destaca que este processo psicoterapêutico não é um brincar por brincar, tem fundamentos teóricos e objetivos a serem alcançados, em vista disso, o tempo de duração do processo psicoterapêutico dependerá de cada criança e de sua subjetividade.

\begin{abstract}
"Através do brincar, a criança conhece o Mundo, e com ele, conhece as pessoas, as relações e regras sociais; pode imitar o adulto, expressando conflitos, além de, ao brincar, serem transmitidos conhecimentos educacionais e este ser igualmente um indicativo do desenvolvimento da criança: as brincadeiras duma criança podem ser indicativas de alguma dificuldade ou desenvolvimento tardio em determinado aspecto, visível aos pais e outros adultos que contactam diariamente com a criança. " (HOMEM, 2009, p. 37)
\end{abstract}

A psicologia vem ampliando seu papel ao que concerne o tratamento e acompanhamento psicoterapêutico da criança autista. O papel do psicólogo passa a ser mediador do desenvolvimento dessa criança, inclusive irá trabalhar com a criança de forma a instrumentalizá-la para a mesma desenvolver autonomia, independência, ampliar seu repertório de comunicação, sociabilização, empatia e o próprio processo educacional. Além disso, o psicólogo desempenha uma função de extensor das relações sociais da criança, e estimulador da comunicação verbal e/ou gestual. A criança através do contato com o psicólogo pode aprender a se comunicar da melhor maneira possível o que ela sente e deseja.

Atualmente, os estímulos provocados pelos autistas, como forma de autoestimulação, levantam um olhar diferenciado. Os comportamentos estimuladores, ou no inglês stimming, funcionam como um buscador de foco, pensamento, concentração, entre outros, é uma forma de estimular um sentido. Sendo assim, a psicologia procura entender os stims para trabalhar com aquilo que a criança já tem formulado. Neste processo, Barros e Fontes (2016) argumentam que o psicólogo não vai restringir os stims, pois entende-se como uma forma de bloquear estímulos excessivos e transbordantes, exemplos de stims são, flapping (chacoalhar as mãos), andar de um lado para outro, balançarse para frente e para trás, cheirar objetos, etc. Stims que funcionam como autoagressão ou heteroagressão devem ser evitados.

Nota-se que algumas crianças autistas desenvolvem uma linguagem repetitiva, ao qual chamamos de ecolalia. A ecolalia é comum em crianças do espectro autista e consiste na repetição de palavras ou trechos de um diálogo, desenho, música, filmes, etc., descontextualizada e carente do singular (BARROS; FONTE, 2016). Sendo assim, para os mesmos autores o psicoterapeuta trabalhará com palavras objetivas, evitando formulação de frases e sempre utilizar como recurso objetos, possibilitando a atribuição de seu significado, desta forma a criança absorve melhor as funções de cada item e seus respectivos nomes. Assim, percebe-se que a psicoterapia e o canabidiol demonstrou avanços significativos, uma vez que a criança melhora percepção, audição e hiperatividade, destinando seu foco a atividades prazerosas.

O psicoterapeuta deve saber conduzir e explorar as habilidades de hiperfoco, ou seja, habilidades destinadas a uma área específica ou mais, que proporciona a criança um saber mais elevado do que o esperado para sua faixa 
etária. Deve-se valorizar e validar toda forma de conhecimento e comunicação da criança, criando caminhos para autonomia, desenvolvimento global e protagonismo, desse modo, trabalha-se autoestima e confiança. A proposta dessa psicoterapia é criar espaço para que a criança se sinta acolhida e perceba que seu conhecimento é aceito, que ela não chega vazia em um processo psicoterápico.

É sabido, que dentro da psicologia existem diferentes abordagens terapêuticas, e cada abordagem trabalha com recursos diferentes, mas atualmente, as formas de comunicação alternativa mais utilizadas são ABA (análise aplicada do comportamento) esta técnica visa modificar comportamentos desadaptativos ou inserir novos comportamentos. PECS (sistema de comunicação por troca de figuras) onde o psicoterapeuta trabalha com blocos de figuras ensinando a criança a utilizar a mesma como recurso de comunicação. TEACCH (tratamento e educação para autistas e crianças com déficits relacionados com a comunicação) consiste em um programa psicoeducacional que proporciona aprendizagens educativas para a criança autista (BIASÃO, 2014). Estas técnicas são aplicadas através de cartões com figuras, uma vez que a criança autista tem a aprendizagem visual mais desenvolvida.

Além disso, alguns profissionais da psicologia estão trabalhando com a abordagem DIR/floortime (tempo de chão), como explica Piacentini, Goldstein e Capelli (2011) nesta técnica o terapeuta se utiliza do brincar para interagir, desenvolver e criar novos repertórios na criança. Através do brincar pode-se acessar partes da criança que outras técnicas não possibilitam, nesta abordagem trabalha-se com o desenvolvimento sensorial e motor da criança, para então desenvolver fala e interação social (PIACENTINI; GOLDSTEIN; CAPELLI, 2011). Entende-se que os recursos utilizados no tratamento da criança com TEA, com finalidade de desenvolver novas habilidades dependerá tanto da faixa etária que a criança está quanto da dinâmica de funcionamento da mesma. Ao iniciar a psicoterapia o psicólogo e a equipe interdisciplinar realizam uma avaliação e formulam um plano de tratamento adequado a cada sujeito.

Assim, o uso do óleo de CBD em crianças com TEA proporciona tanto na psicoterapia quanto nas técnicas citadas acima, recursos de autorregulação, atenção compartilhada, diminuição de obsessão e do perfil desafiador e desatenção, proporcionando na psicoterapia melhor engajamento da criança, trabalhos para compreensão e desenvolvimento da previsibilidade, onde o psicólogo comunica alguma mudança na rotina para a criança e aguarda um tempo para que essa comunicação seja elaborada, melhorando na cognição da criança, processo de receber e entender comandos e estabilidade motora. Compreende-se, portanto, que os benefícios do óleo de canabidiol são inúmeros, mas em conjunto com atividades psicoterapêuticas propicia um trabalho integral com a criança, ao ampliar e modificar a visão de um sujeito que apenas recebe comandos e é reforçado, para um sujeito que pode se desenvolver de forma totalitária.

Ademais, o vínculo estabelecido dentro do processo terapêutico favorece a abertura para que o psicólogo mergulhe no mundo da criança, embora o brincar da criança autista seja um brincar concreto. Contudo, todas as ações e comportamentos dentro das brincadeiras trazem possibilidade de 
desenvolvimento cognitivo, físico e expansão de repertório. Conforme Martins e Góes (2013), a família deve identificar e interpretar toda forma de brincar da criança autista, visto que, é uma forma de comunicação. Por trás das brincadeiras, a criança inicia um processo de desenvolvimento psíquico e pode construir o brincar imaginário. Durante o brincar no espaço psicoterapêutico, o psicólogo trabalha com o autista o contato visual e físico, verbalização, funções dos brinquedos, trocas de brincadeiras durante a sessão, intolerância a frustração, afetividade e desenvolvimento sensorial (MARTINS; GÓES, 2013).

Segundo Lopes (2014), autistas que fazem uso de fármacos e iniciam o uso do canabidiol gradativamente vão diminuindo as dosagens dos fármacos, e aos poucos, ocorre a substituição gradual ou total pelo óleo da $C$. sativa. Todos esses benefícios corroboram com a psicologia e os trabalhos propostos, uma vez que o canabidol atua como redutor da ansiedade e hiperatividade, possibilitando a diminuição e/ou controle dos comportamentos repetitivos e estereotipados, agressividade, esquiva social e medo. Todos esses benefícios atuam em conjunto com a psicoterapia e possibilitam grandes avanços para a construção da socialização e desenvolvimento das funções comprometidas (LOPES, 2014).

Neste processo, o uso do óleo da C. sativa, desenvolve uma função importante no corpo humano, regulando todo o organismo do sujeito, modificações na percepção, pensamento e humor (LOPES, 2014). Em conjunto com essa regulação que a psicologia vem desenvolvendo uma nova identidade. Através disso, o processo psicoterapêutico potencializa as aptidões da criança autista, proporciona aprendizagem, resoluções de conflitos, entrega ao desconhecido, além disso, é um trabalho de intervenção no comportamento. $O$ psicoterapeuta traz a criança para "junto", acolhendo o mesmo, mostrando sua inteira disponibilidade e dedicação, respeitando o tempo da criança. Portanto, é desta forma que a psicologia deve atuar, se dedicando a criança autista, demonstrando de formas distintas que a compreende e que a comunicação está ocorrendo.

Assim também, dentro do processo psicoterapêutico, a criança precisa estar disposta e disponível para o terapeuta, e quando o mesmo sabe cada efeito ocasionado pelos fármacos e canabidiol, ele também identifica as manifestações fisiológicas, separando o que é da criança e o que é efeito da droga. Porquanto, o canabidiol, assim como qualquer outra medicação, traz consigo alguns efeitos colaterais, como apontam Schleider, Meiri e Novack (2019) por exemplo, a sonolência e relaxamento do tônus muscular, porém ao se fazer uma comparação com as classes de fármacos citados acima que provocam inquietação, sonolência, insônia, efeito psicoativo, aumento do apetite (provocando obesidade), problemas digestivos, boca seca e falta de apetite, os efeitos do CBD são menos agressivos ao organismo e não trazem consequências adversas.

\section{CONCLUSÃO}

O presente artigo teve como problemática a discussão dos efeitos do canabidiol e, sua respectiva contribuição no processo psicoterapêutico da criança com Transtorno do Espectro Autista. Em virtude dos fatos mencionados, 
as contribuições do canabidiol no processo psicoterapêutico são, a melhora no trabalho do desenvolvimento e integração sensorial, ampliação das relações sociais e comunicação, sendo elas verbal ou não-verbal, relaxamento do tônus muscular, melhorando a execução das atividades manuais e o reconhecimento do próprio corpo, atenção, percepção, redução de comportamentos agressivos, crescimento do repertório espaço-temporal e auxiliador na dessensibilização de fármacos.

Contudo, apontamos que o uso do fitoterápico deve ocorrer sob prescrição médica de dosagens, assim, há uma melhora significativa no cotidiano da criança com TEA, associando o uso do canabidiol com a psicoterapia, a criança com TEA apresenta diminuição de sintomas, aproveitando melhor este tratamento. Neste prisma, sabendo das diversas propriedades que a Cannabis sativa tem, deve-se realizar novas pesquisas sobre essas substâncias e seu potencial terapêutico. Faz-se necessário que outras pesquisas mais específicas na área da Psicologia, com esta temática, sejam desenvolvidas, de modo que colaborem para a publicação da relação entre o canabidiol, psicoterapia e o TEA.

\section{REFERÊNCIAS}

BARROS, A.; PERES, M. Proibição da maconha no Brasil e suas raízes históricas escravocratas: Proibição da Maconha no Brasil. Revista Periferia, v. 3, n. 2, 2011. Disponível em: file:///C:/Users/ACER/Downloads/3953-15156-1PB\%20(2).pdf. Acesso em: 7 de maio 2019.

BARROS, I. B. R.; FONTE, R. F. L. Estereotipias motoras e linguagem: aspectos multimodais da negação no autismo. Revista Brasileira de Linguística Aplicada, v. 16, n. 4, p. 745-763, 2016. Disponível em: http://www.scielo.br/pdf/rbla/v16n4/1984-6398-rbla-16-04-00745.pdf. Acesso em: 24 mar. 2019.

BIASÃO, M. C. R. Transtorno do Espectro Autista (TEA). In: MORI, N. N. R.; CEREZUELA, C. Transtornos Globais do Desenvolvimento e Inclusão: Aspectos Históricos, Clínicos e Educacionais. Maringá: Eduem, 2014. p. 115129.

BUENO, C. Q. Alterações na percepção emocional em usuários de cannabis. Revista de Biologia, v. 13, n. 1, 2018. Disponível em: http://www.revistas.usp.br/revbiologia/article/view/109134/107639. Acesso em: 10 jan. 2019.

Cartilha Direitos das pessoas com Autismo. Cartilha, n. 1, 2011. Disponível em: https://www.revistaautismo.com.br/CartilhaDireitos.pdf. Acesso em: 22 fev. 2019.

COLLUCCI, C. Mãe de menina com autismo obtém autorização para plantar maconha em casa. Folha de São Paulo, 2019. Disponível em: https://www1.folha.uol.com.br/equilibrioesaude/2019/02/mae-de-menina-com- 
autismo-obtem-autorizacao-para-plantar-maconha-em-casa.shtml. Acesso em: 3 jun. 2019.

CRIPPA, J. A. S. et al. Intoxicação por $\triangle 9$-THC pelo extrato de cannabis enriquecido com canabidiol em duas crianças com epilepsia refratária: remissão completa após a mudança para o canabidiol purificado. Frontiers in Pharmacology, v. 7, p. 1-6, 2016. Disponível em: https://www.ncbi.nlm.nih.gov /pmc/articles/PMC5043219/pdf/fphar-07-00359.pdf. Acesso em: 24 fev. 2019.

FITZPATRICK, S. E. et al. Agressão no transtorno do espectro autista: opções de apresentação e tratamento. Neuropsychiatric Disease and Treatment, ed. 12, p. 1525-1538, 2016. Disponível em: https://www.ncbi.nlm.nih.gov/pmc/ articles/PMC4922773/pdf/ndt-12-1525.pdf. Acesso em: 14 mar. 2019.

FRANZIN, S. O Diagnóstico e a Medicalização. In: MORI, N. N. R; CEREZUELA, C. Transtornos Globais do Desenvolvimento e Inclusão: Aspectos Históricos, Clínicos e Educacionais. Maringá: Eduem, 2014, p. 63-92.

HOMEM, C. A Ludoterapia e a Importância do Brincar: Reflexões De Uma Educadora De Infância. Cadernos de Educação de Infância, n. 88, p. 21-24, 2009. Disponível em: http://apei.pt/upload/ficheiros/edicoes/CEl_88_Artigo2.pdf. Acesso em: 2 mar. 2019.

LEMOS, C. J. M. A.; ROSA, P. O. No caminho da rendição: cannabis, legalização e antiproibicionismo. Argumentum, v. 7, n. 1, p. 69-92, 2015. Disponível em: http://periodicos.ufes.br/argumentum/article/view/9045/7248. Acesso em: 3 jun. 2019.

LIMA, T. C.; MIOTO, R. C. T. Procedimentos metodológicos na construção do conhecimento científico: a pesquisa bibliográfica. Revista Katál, v. 10, p. 37-45, 2007. Disponível em: file:///C:/Users/ACER/Downloads/1030-19096-1-PB.pdf. Acesso em: 1 abr. 2019.

LOPES, R. J. R. M. Canabinoides ajudam a desvendar aspectos etiológicos em comum e trazem esperança para o tratamento de autismo e epilepsia. Revista da Biologia, v. 13, n. 1, p. 43-59, 2014. Disponível em: https://repositorio.unb.br/ bitstream/10482/24436/3/ARTIGO_CanabinoidesAjudamDesvendar.pdf. Acesso em: 15 jan. 2019.

LOPES, R. J. R. M.; RIBEIRO, S. Maconha, cérebro e saúde. Coleção CIÊNCIA no bolso. Rio de Janeiro: Vieira e Lent, 2007,163 p.

MARTINS, A. D. F.; GÓES, M. C. R. Um estudo sobre o brincar de crianças autistas na perspectiva histórico-cultural. Revista Semestral da Associação Brasileira de Psicologia Escolar e Educacional, v. 17, n. 1, p. 25-34, 2013. Disponível em: http://www.scielo.br/pdf/pee/v17n1/a03v17n1.pdf. Acesso em: 10 jan. 2019. 
OLIVEIRA, K. G.; SERTIÉ, A. L. Transtornos do espectro autista: um guia atualizado para aconselhamento genético. Revendo Ciências Básicas, v. 15, n. 2, p. 233-238, 2017. Disponível em: http://www.scielo.br/pdf/eins/v15n2/pt_ 1679-4508-eins-15-02-0233.pdf. Acesso em: 15 jan. 2019.

PIACENTINI, P.; GOLDSTEIN, A.; CAPELLI, D. D- Desenvolvimento. In: PIACENTINI, P.; GOLDSTEIN, A.; CAPELLI, D. Brincar é desenvolver: um caminho para o mundo do autista. Recife: Libertas, 2011, p. 14-24.

POSAR, A.; VISCONTI, P. Sensory abnormalities in children with autism spectrum disorder. Jornal de Pediatria, v. 94, n 4, p. 344-350, 2018. Disponível em: $\quad$ http://www.scielo.br/pdf/jped/v94n4/pt_0021-7557-jped-94-04-0342.pdf. Acesso em: 20 mar. 2019.

SANTOS, A. H. Efeitos do canabidol no comportamento agressivo induzido por isolamento social em camundongos. 2016. 174 f. Dissertação (mestrado em ciências) Universidade de São Paulo, Ribeirão Preto, 2001.

SECRETARIA DE ESTADO DE SAÚDE. Substâncias da maconha. Governo do Estado Mato Grosso Do Sul. 2015. Disponível em: http://www.saude.ms.gov.br/substancias-da-maconha/. Acesso em 12 de jan. de 2019.

SERRANO, P. Os Sistemas Sensoriais. In: SERRANO, P. A integração sensorial - No desenvolvimento e aprendizagem da criança. Lisboa: PapasLetras, 2015, p. 13-25.

SILVA, M.; MULICK, J. A. Diagnosticando o Transtorno Autista: Aspectos Fundamentais e Considerações Práticas. Psicologia Ciência e Profissão, v. 29, n. 1, p. 116-131, 2009. Disponível em: http://www.scielo.br/pdf/pcp/v29n1/ v29n1a10.pdf. Acesso em: 25 fev. 2019.

SOCIEDADE BRASILEIRA DE PEDIATRIA. Triagem precoce para o autismo/ Transtorno do Espectro Autista. Departamento Científico de Pediatria do Desenvolvimento e Comportamento: n. 1, 2017. Disponível em: https://www.sbp.com.br/fileadmin/user_upload/2017/04/19464b-DocCientAutismo.pdf. Acesso em: 20 de fev. de 2019.

SOUZA, J. C. et al. Atuação do Psicólogo Frente aos Transtornos Globais do Desenvolvimento Infantil. Psicologia Ciência E Profissão, v. 24, n. 2, p. 24-31, 2004. Disponível em: http://www.scielo.br/pdf/pcp/v24n2/v24n2a04.pdf. Acesso em: 24 mar. 2019.

SCHLEIDER, L. B. L. et al. Experiência real do tratamento médico da maconha no autismo: análise de segurança e eficácia. Scientific Reports, p. 1-7, 2019, janeiro 2019. Disponível em: https://www.nature.com/articles/s41598-01837570-y\#citeas. Acesso em: 22 fev. 2019. 
WALLACE, S. Às vezes, meu filho é agressivo - o que pode ajudar?. Autism Speaks, 2018. Disponível em: https://www.autismspeaks.org/expert-opinion/mychild-sometimes-aggressive-what-can-help. Acesso em: 13 mar. 2019. 